\title{
EDITORIAL
}

\section{EARLY PHYSICAL THERAPY INTERVENTION CAN REDUCE THE CHANCE OF RESPIRATORY COMPLICATIONS IN COVID-19}

*Syed Alamdar Hussain; Lecturer, College of Physical Therapy. Northwest Institute of Health Sciences. Peshawar. Pakistan Raheela Kanwal; Chief editor The Rehabilitation Journal \& Assistant Professor, College of Applied Medical Sciences University of Hail, Hail, Kingdom of Saudi Arabia

Huma Balqias; Junior Lecturer, Rehman College of Rehabilitation Sciences. Peshawar Pakistan Usman Farooq; Lecturer, College of Physical Therapy. Northwest Institute of Health Sciences. Peshawar. Pakistan *Email: syedalamdarhussein@gmail.com Citation: Hussain SA, Kanwal R, Balqias H, Farooq U. Early physical therapy intervention can reduce the chance of respiratory complications in COVID-19. T Rehabili. J, 2020:04(01); 137-138 soi: 21-2017/re-trjvol04iss01p137 Since the start of 2020, a COVID-19 emerged as a new strain of Coronavirus. Initially, it affected the population of Wuhan, China and after that it outspread all over the world and was declared as a pandemic by World Health Organization on 30th January, $2020 .^{1}$ It has been identified that COVID-19 can cause mild illness including common cold to more severe condition known as acute respiratory distress syndrome (ARDS), if not treated promptly. ${ }^{2}$ While people of all ages are susceptible to COVID-19, those over 60 years of age and with cardiovascular diseases along with diabetes have even more chances of becoming seriously ill Whereas children seem to be less affected. ${ }^{3}$ Currently there is no pharmacological treatment, still some antiviral drugs have been proven to be helpful along with plasma transfusion in which plasma is extracted from the blood of patient who got recovered from COVID-19 an is transfused into the patient still suffering from the said disease. ${ }^{4}$

Symptoms of respiratory complications due to this disease influence the mind of a Physical Therapist (PT). Though after discussing the maneuvers of respiratory Physical Therapy with fellow professional colleagues as well as clinicians and practically applying it on respective relatives, friends and advice seekers after getting the informed consent from them; those who started to have initial symptoms of COVID-19 before being tested positive and then later got positive. It resulted in great ease for most of them to breathe and did not led to serious respiratory complications that include dyspnea and accumulation of thick and tenacious secretions inside the lungs, which ultimately is a precursor of pneumonia. Following were the PT interventions suggested to the patients showing acute symptoms;

Steam inhalation, breathing exercises and postural drainage positions were inculcated in the treatment plan and guided respectively, steam inhalation therapy is normally advised to be used as primary care in acute respiratory diseases. ${ }^{5}$ It is most commonly used therapy at home and is inexpensive, moreover it promotes self-reliance in the patients; it is used therapeutically by inhaling steam through nose so that it reaches the respiratory system. ${ }^{6-8}$ Steam inhalation helps in loosening the mucus, it opens the nasal airway passages decreases mucosal inflammation and heat can prevent replication of viruses. ${ }^{9}$ It helps to relax muscles and relieves coughing by preventing excessive dryness in the mucosal membranes. ${ }^{10}$

Moreover, breathing exercises have been reported to have beneficial effects in improving symptoms and optimizing pulmonary function in patients. Breathing programs have been reported to have positive effects in alleviating symptoms and optimizing pulmonary function in patients. ${ }^{11}$ Breathing exercises aim to improve the individuals breathing pattern and increase in lung expansion, they also enhance the performance of respiratory muscles thus leading towards increase in functional residual capacity, and inspiratory reserve volume. ${ }^{12}$ Breathing exercises reduces breathlessness, increase exercise capacity and improve overall well-being of a person ${ }^{13,14,15,16}$ The physiological effect of breathing exercises comprises of increase in intra-bronchial pressure thus preventing the collapse of bronchi and leading towards increase in inspiratory and expiratory flow rate. ${ }^{13,15}$ It act by stimulating the autonomic system thereby promoting relaxation and in return improves the physiological parameters. $^{16}$

Furthermore, body positioning improves the efficiency and effectiveness of both primary and accessory muscles of breathing leading to ease in dyspnea and reduction in work of breathing. ${ }^{17}$ These positions improve the ventilation perfusion ratio and utilize the gravity to remove secretions. ${ }^{18}$ Positioning decrease the ventilation demand resulting in longer expiratory time thereby preventing hyperinflation and ultimately resolving dyspnea. ${ }^{19}$

As a healthcare professional and specially a Physical Therapist we would like to ask the imminent researchers to fill this gap by conducting different surveys and trials. Through our experience we've found that the manoeuvres we applied have been very effective and improved the overall outcome of the patients suffering from COVID -19.

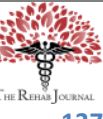




\section{REFERENCES}

1. Sohrabi C, Alsafi Z, O'Neill N, Khan M, Kerwan A, Al-Jabir A, et al. World Health Organization declares global emergency: A review of the 2019 novel coronavirus (COVID-19). Int J Surg . 2020;76:71-76. doi: 10.1016/j.ijsu.2020.02.034.

2. Wickramaratchi MM, Pieris A, Fernando AJS. Review on Identification of Major Infectious Site and Disease Progression Pathway for Early Detection of Novel Corona Virus Covid-19. 2020.

3. Ezekiel J Emanuel, Govind Persad, Ross Upshur, Beatriz Thome, Michael Parker, Aaron Glickman, et al. Fair Allocation of Scarce Medical Resources in the Time of Covid-19. N Engl J Med. 2020;382(21):2049-2055. doi:10.1056/NEJMsb2005114.

4. Anudeep T, Jeyaraman M, Shetty DU, Raj H, Ajay S, Rajeswari Somasundaram VKV, et al. Convalescent Plasma as a plausible therapeutic option in nCOVID-19-A Review. J Clin Trials. 2020;10(409): do i : 10. 35248/2167-0870. 20. 10. 409

5. Little $\mathrm{P}$, Moore M, Kelly J, Williamson I, Leydon G, McDermott L, et al. Ibuprofen, paracetamol, and steam for patients with respiratory tract infections in primary care: pragmatic randomised factorial trial. BMJ. 2013;347:f6041.

6. Baartmans M, Kerkhof E, Vloemans J, Dokter J, Nijman S, Tibboel D, et al. Steam inhalation therapy: severe scalds as an adverse side effect. Br J Gen Pract. 2012;62(600):e473-7. doi: 10.3399/bjgp12X652337.

7. Umoren R, Odey F, Meremikwu MM. Steam inhalation or humidified oxygen for acute bronchiolitis in children up to three years of age. Cochrane Database Syst Rev . 2011;(1):CD006435. doi: 10.1002/14651858.CD006435.pub2.

8. Parisius LM, Stock-Schröer B, Berger S, Hermann K, Joos S. Use of home remedies: a cross-sectional survey of patients in Germany. BMC Fam Pract . 2014;15:116. doi: 10.1186/1471-2296-15-116.

9. Brewster CT, Choong J, Thomas C, Wilson D, Moiemen N. Steam inhalation and paediatric burns during the COVID-19 pandemic. Lancet . 2020;395(10238):1690. doi: 10.1016/S0140-6736(20)31144-2.

10. Rawat $\mathrm{H}$, Gupta $\mathrm{H}$. Effectiveness of steam inhalation with tulsileaves along with turmeric versus steam inhalation with plain water to relieve respiratory symptoms of nasal congestion among children. Baba Farid Un Nurs. J. 2015;9(2):6-10.

11. Liu F, Cai H, Tang Q, Zou Y, Wang H, Xu Z, et al. Effects of an animated diagram and video-based online breathing program for dyspnea in patients with stable COPD. Patient Prefer Adherence. 2013; 7: 905-913. doi: 10.2147/PPA.S43305

12. Grams ST, Ono LM, Noronha MA, Schivinski Cl, Paulin E. Breathing exercises in upper abdominal surgery: a systematic review and metaanalysis. Rev Bras Fisioter. 2012;16(5):345-53. doi: 10.1590/s1413-35552012005000052.

13. Waqar Ahmed Awan, Noor Abid, Anees Rafiq Rao, Muhammad Naveed Babar, Misha Ansari. Effect of deep breathing exercises in healthy smokers: A pilot study. J Pak Med Assoc. 2020; 70(7): 1209-1213. doi.org/10.5455/JPMA.16551

14. Holland AE, Hill CJ, Jones AY, McDonald CF. Breathing exercises for chronic obstructive pulmonary disease. Cochrane Database Syst. Rev. 2012; 10. DOI: 10.1002/14651858.CD008250.pub2.

15. Visser FJ, Ramlal S, Dekhuijzen PR, Heijdra YF. Pursed-lips breathing improves inspiratory capacity in chronic obstructive pulmonary disease. Respiration . 2011;81(5):372-8. doi: 10.1159/000319036.

16. Garrod R, Mathieson T. Pursed lips breathing: are we closer to understanding who might benefit. Chron Respir Dis . 2013;10(1):3-4. doi: $10.1177 / 1479972312472689$.

17. Booth S, Burkin J, Moffat C, Spathis A. Positions to Ease Breathlessness. Managing Breathlessness in Clinical Practice: Springer; 2014: 4965.

18. Bott J. Non-pharmacological management of breathlessness. Managing Breathlessness in the Community. 2013:113.

19. Yates P, Schofield P, Zhao I, Currow D. Supportive and palliative care for lung cancer patients. J Thorac Dis . 2013;5 Suppl 5(Suppl 5):S623-8. doi: 10.3978/j.issn.2072-1439.2013.10.05. 